OPEN ACCESS

Edited by:

Guillaume Turc,

Centre Hospitalier

Sainte-Anne, France

Reviewed by:

Eleni Korompoki,

National and Kapodistrian University of Athens Medical School, Greece Else Charlotte Sandset,

Oslo University Hospital, Norway

${ }^{*}$ Correspondence:

Weidong Liu

sdlclwd@163.com

Liyong Zhang

13346256936@163.com

Specialty section: This article was submitted to

Stroke,

a section of the journa

Frontiers in Neurology

Received: 27 September 2020 Accepted: 15 January 2021

Published: 11 March 2021

Citation:

Liu W, Zhuang X and Zhang L (2021) Prognostic Value of Blood Pressure Variability for Patients With Acute or Subacute Intracerebral Hemorrhage: A Meta-Analysis of Prospective

Studies. Front. Neurol. 12:606594. doi: 10.3389/fneur.2021.606594

\section{Prognostic Value of Blood Pressure Variability for Patients With Acute or Subacute Intracerebral Hemorrhage: A Meta-Analysis of Prospective Studies}

\author{
Weidong Liu ${ }^{1 *}$, Xianbo Zhuang ${ }^{2}$ and Liyong Zhang ${ }^{1 *}$ \\ 1 Department of Neurosurgery, Liaocheng People's Hospital, Liaocheng, China, ${ }^{2}$ Department of Neurology, Liaocheng \\ People's Hospital, Liaocheng, China
}

The results on the role of systolic blood pressure (SBP) variability in the functional outcome for patients with intracerebral hemorrhage $(\mathrm{ICH})$ have been inconsistent. Hence, this meta-analysis of prospective studies was conducted to assess the association between SBP variability and poor outcomes in patients with acute or subacute $\mathrm{ICH}$. PubMed, Embase, and the Cochrane Library were electronically searched for eligible studies from their inception to July 2020. The role of SBP variability assessed using standard deviation (SD), coefficient of variation (CV), successive variation (SV), average real variability (ARV), and residual standard deviation (RSD) in the risk of poor functional outcomes were assessed using odds ratio (OR) with 95\% confidence interval (Cl) through the random-effects model. Seven prospective studies involving 5,201 patients with ICH were selected for the final meta-analysis. Increased SBP variability was associated with an increased risk of poor functional outcomes, regardless of its assessment using SD (OR: $1.38 ; 95 \% \mathrm{Cl}: 1.14-1.68 ; P=0.001), \mathrm{CV}$ (OR: $1.98 ; 95 \% \mathrm{Cl}: 1.13-3.47 ; P=0.017)$, SV (OR: 1.30; 95\% Cl: 1.08-1.58; $P=0.006)$, ARV (OR: 1.13; 95\% Cl: 1.03-1.24; $P=0.010)$, or RSD (OR: 1.22; 95\% Cl: 1.00-1.50; $P=0.049$ ). Moreover, the role of SBP variability in the risk of poor functional outcomes for patients with $\mathrm{ICH}$ was affected by country, study design, mean age, stroke type, outcome definition, and study quality. This study indicated that SBP variability was a predictor of poor outcomes for patients with $\mathrm{ICH}$.

Keywords: blood pressure variability, intracerebral hemorrhage, prognosis, systolic blood pressure, neurosurgery

\section{INTRODUCTION}

Stroke is the second leading cause of death, accounting for nearly $10 \%$ of all deaths worldwide (1). Moreover, it is considered the leading cause of permanent disability and accounts for $5 \%$ of the loss of all disability-adjusted life-years (2). Hemorrhagic stroke accounts for nearly $15 \%$ of all stroke cases and contributes more to the loss of disability-adjusted life-years compared with ischemic stroke $(2,3)$. The most common pathophysiological mechanism for acute intracerebral hemorrhage (ICH) was chronic arterial hypertension with the rupture of microscopic pseudoaneurysms in the basal ganglia, thalami, pons, midbrain, and cerebellum (4-6). Furthermore, ICH is characterized 
by high morbidity, acute onset, and high recurrence, disability, or mortality rate; the mortality rate within 30 days ranged from 30 to $40 \%(7,8)$.

Ambulatory blood pressure (BP) monitoring during a daily cycle was better than traditional clinic BP monitoring to detect $\mathrm{BP}$ values for an accurate assessment of BP control and the prognosis of various diseases $(9,10)$. It could be used to calculate the intraindividual fluctuation in BP levels within $24 \mathrm{~h}$. Studies have already found that BP variability is significantly associated with organ damage and cardiovascular events (11-13). Several systematic reviews and meta-analyses were conducted to assess the role of BP variability in the progression of stroke (14-18). However, the prognostic role of BP variability for patients with acute stroke was less addressed. Manning et al. conducted a systematic review of 18 studies and found that greater systolic BP variability was associated with poor functional outcomes in patients with acute stroke, while only two of the included studies focused on patients with ICH (19). Therefore, this metaanalysis of prospective studies was performed to assess the potential prognostic role of systolic BP variability in patients with ICH.

\section{METHODS AND MATERIALS}

\section{Data Sources, Search Strategy, and Selection Criteria}

This study was performed and reported following the Metaanalysis of Observational Studies in Epidemiology protocol (20). It investigated the role of systolic BP variability in patients with $\mathrm{ICH}$, with no restriction on publication language and status. The electronic databases of PubMed, Embase, and the Cochrane Library were systematically searched to select eligible studies from their inception up to July 2020. The search terms were as follows: ("Stroke" or "cerebr* vascular disease" or "intracerebr* hemorrhage" or "cerebr* hemorrhage" or "brain hemorrhage") and ("blood pressure variability" or "BPV") and ("outcome*" or "prognos" or "predict" or "mortality" or "death" or "dependence*" or "disability" or "neurological deterioration" or "functional dependence*"). The reference lists from retrieved studies were also manually searched to identify any new study meeting the inclusion criteria. The subject heading, design, disease status, exposure, and prognostic outcomes of eligible studies were applied to select potentially relevant studies.

The literature search and study selection were conducted by two reviewers independently, and any inconsistency was resolved with the help of an additional reviewer. The inclusion criteria were as follows: (1) patients: all patients with $\mathrm{ICH}$; and (2) exposure: systolic BP variability, including assessment using standard deviation (SD), coefficient of variation (CV), successive variation (SV), average real variability (ARV), and residual standard deviation (RSD); the systolic BP variability parameters were calculated both per $10 \mathrm{~mm} \mathrm{Hg}$ shift and in quintiles (19); (3) outcomes: poor functional outcome, with the outcome definition given; and (4) study design: prospective studies, including prospective cohort and follow-up randomized controlled trials.

\section{Data Collection and Quality Assessment}

The following data from the studies included were independently collected by two reviewers: first author or study group's name, publication year, country, study design, sample size, mean age, male proportion, stroke phase, systolic BP targets, systolic BP variability, time from stroke onset to recruitment, BP measurement, outcome definition, follow-up duration, covariates adjusted, and effect estimate and its 95\% CI. The effect estimate based on crude data and with maximally adjusted covariates was selected if the study reported several multivariable-adjusted effect estimates. The study quality was assessed using the NewcastleOttawa Scale (NOS), which was based on selection (four items), comparability (one item), and outcome (three items); the scoring system ranged from 0 to 9 (21). Any study with eight or nine stars was considered to be of high quality. Any inconsistencies between the two reviewers for data collection and quality assessment were settled by discussion until a consensus was reached.

\section{Statistical Analysis}

The prognostic role of systolic BP variability in patients with $\mathrm{ICH}$ was assigned as effect estimate [odds ratio (OR), relative risk, and hazard ratio] and 95\% confidence interval (CI) in each individual study. After this, the random-effects model was applied to calculate the pooled ORs and 95\% CIs for SD, CV, SV, ARV, and RSD of systolic BP variability $(22,23)$. Heterogeneity across included studies was assessed using $I^{2}$ and $Q$ statistic, and a $P$-value $<0.10$ indicated significant heterogeneity $(24,25)$. Sensitivity analysis was conducted to assess the stability of pooled conclusions by sequentially excluding individual studies (26). Subgroup analyses for the risk of poor outcomes related to systolic BP variability by SD and CV were conducted based on country, study design, mean age, stroke type, outcome definition, and study quality, and the interaction $P$-value was applied to assess the difference between subgroups (27). Publication biases for poor outcomes related to systolic BP variability assessed using SD, CV, SV, and ARV were evaluated with funnel plots, Egger's test, and Begg's test $(28,29)$. The inspection level for all pooled analyses were two-sided, and $P<0.05$ was regarded as statistically significant. Stata software (version 10.0; Stata Corporation, TX, USA) was applied to conduct all statistical analyses.

\section{RESULTS}

\section{Literature Search}

The details regarding the literature search and study selection are summarized in Figure 1. Overall, 894 records were obtained from initial electronic searches, and 841 were excluded because of duplicate titles and irrelevant studies. A total of 53 studies were retrieved for further full-text evaluations, and 46 studies were excluded due to the following reasons: patients with ischemic stroke $(n=27)$, retrospective design $(n=16)$, and review or meta-analysis $(n=3)$. After detailed evaluations, seven prospective studies were selected for the final quantitative metaanalysis (30-36). No new eligible study was detected by manually searching the reference lists of retrieved studies. The baseline 


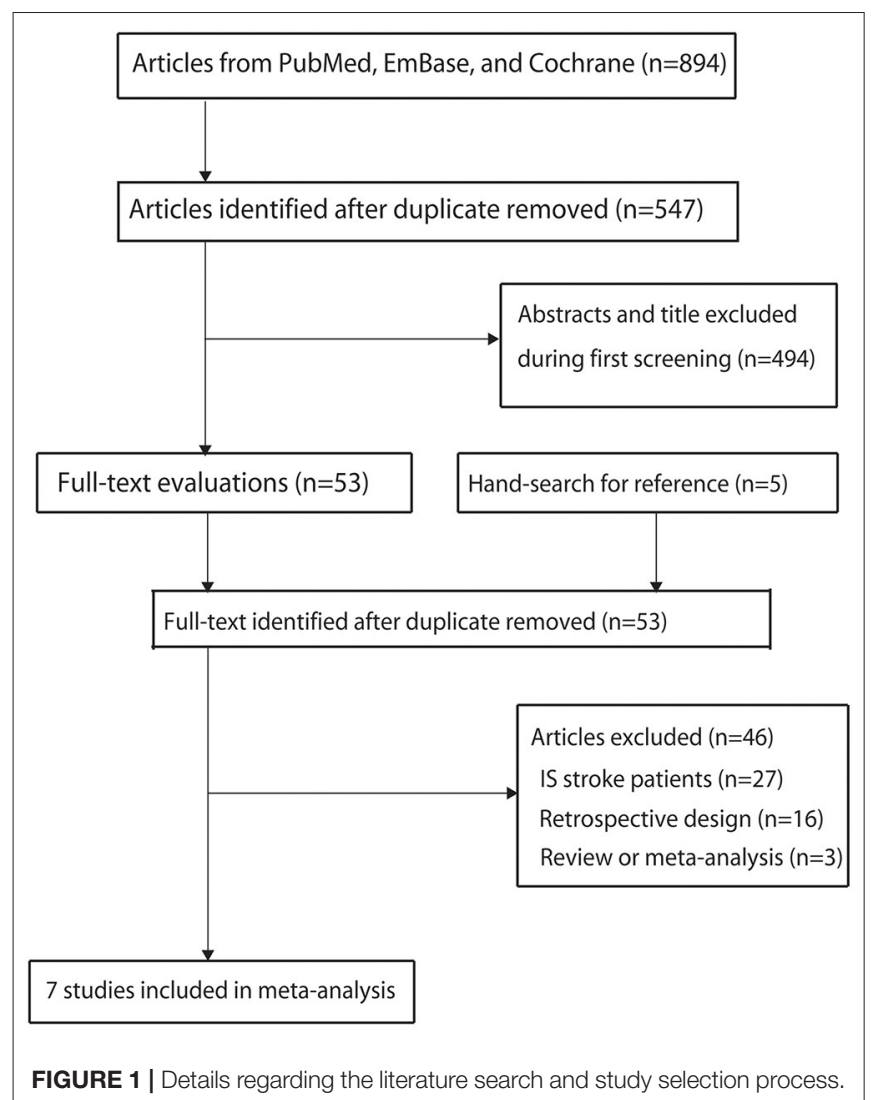

characteristics of the included studies and patients are displayed in Table 1.

\section{Study Characteristics}

Of seven included studies, three were prospective observational studies, and the remaining four were a follow-up of randomized controlled trials. A total of 5,201 patients with ICH were recruited, and 104-2,645 patients were included in each study. Two studies were conducted in multiple countries, two were conducted in the USA, and the remaining three studies were conducted in Asia (China, Japan, and Korea). Two studies included patients in the hyperacute stage, seven included patients in the acute stage, and one included patients in the subacute stage. The study quality was assessed using NOS; two studies had nine stars, two had eight stars, one had seven stars, and the remaining two had six stars.

\section{Meta-Analysis}

The breakdown for the number of studies available for systolic BP variability assessed using SD, CV, SV, ARV, and RSD was $6,5,4,3$, and 2 studies, respectively (Figure 2). Systolic BP variability assessed, using SD (OR: $1.38 ; 95 \% \mathrm{CI}: 1.14-1.68 ; P$ $=0.001$ ), $\mathrm{CV}$ (OR: 1.98; 95\% CI: 1.13-3.47; $P=0.017), \mathrm{SV}$ (OR: 1.30 ; 95\% CI: $1.08-1.58 ; P=0.006$ ), ARV (OR: $1.13 ; 95 \%$ CI: $1.03-1.24 ; P=0.010$ ), or RSD (OR: 1.22 ; 95\% CI: $1.00-$ 1.50; $P=0.049$ ), was associated with an increased risk of poor functional outcomes for patients with $\mathrm{ICH}$. Moreover, significant heterogeneity was noted across included studies for systolic BP variability assessed using $\mathrm{SD}\left(I^{2}=73.7 \% ; P=0.002\right), \mathrm{CV}\left(I^{2}\right.$ $=96.3 \% ; P<0.001)$, and SV $\left(I^{2}=57.5 \% ; P=0.070\right)$, while moderate heterogeneity was observed across included studies for systolic BP variability assessed using ARV $\left(I^{2}=42.3 \% ; P=\right.$ $0.177)$ and $\operatorname{RSD}\left(I^{2}=44.5 \% ; P=0.180\right)$. While pooling crude data, systolic BP variability assessed using SD (OR: 1.54; 95\% CI: $1.05-2.26 ; P=0.028$ ), CV (OR: $1.80 ; 95 \%$ CI: $1.07-3.03$; $P=0.027$ ), SV (OR: $1.45 ; 95 \% \mathrm{CI}: 1.32-1.60 ; P<0.001$ ), and RSD (OR: 1.80 ; 95\% CI: 1.56-2.09; $P<0.001$ ) was found to be associated with an increased risk of poor functional outcomes, whereas ARV was not associated with the risk of poor functional outcomes (OR: 1.31; 95\% CI: 0.98-1.75; $P=0.073$ ) (Figure 3). A significant heterogeneity was observed for systolic BP variability assessed using SD $\left(I^{2}=92.7 \% ; P<0.001\right), \mathrm{CV}\left(I^{2}=92.0 \% ; P<\right.$ $0.001)$, and ARV $\left(I^{2}=93.7 \% ; P<0.001\right)$, while no evidence of heterogeneity was found for systolic BP variability assessed using SV $\left(I^{2}=0.0 \% ; P=0.521\right)$ and $\operatorname{RSD}\left(I^{2}=0.0 \% ; P=0.479\right)$.

\section{Sensitivity Analysis}

The results of sensitivity analyses for the prognostic role of systolic BP variability in the risk of poor functional outcomes are presented in Table 2. First, the prognostic role of systolic $\mathrm{BP}$ variability by $\mathrm{SD}$ was robust and not altered by sequentially excluding individual studies; the pooled OR ranged from 1.24 to 1.54 , and the heterogeneity across included studies remained high. Second, the pooled conclusion for the risk of poor functional outcomes related to systolic BP variability by $\mathrm{CV}$ varied, and the pooled OR ranged from 1.40 to 2.42. Moreover, the heterogeneity across the studies included remained high and was not fully explained by sensitivity analysis. Third, the prognostic role of systolic BP variability by SV in the risk of poor functional outcomes was stable, with no evidence of heterogeneity among the studies included after excluding the FAST-MAG study (35). Fourth, the pooled conclusion on the role of systolic BP variability by ARV varied, with no evidence of heterogeneity after excluding the study conducted by Jeon et al. (34). Finally, the pooled conclusion on the role of systolic BP variability by RSD in the risk of poor functional outcomes was robust, and the pooled OR ranged from 1.15 to 1.45 .

\section{Subgroup Analysis}

Subgroup analyses of the role of systolic BP variability by SD and $\mathrm{CV}$ in the risk of poor functional outcomes were conducted, and the results are presented in Table 3. Systolic BP variability by SD was associated with an increased risk of poor functional outcomes in pooled studies conducted in multiple countries (OR: 1.16; 95\% CI: $1.05-1.28 ; P=0.003$ ), studies designed as the followup of randomized controlled trials (OR: 1.51; 95\% CI: 1.01-2.27; $P=0.045)$, studies with the mean age of patients $<65.0$ years (OR: $1.35 ; 95 \% \mathrm{CI}: 1.11-1.65 ; P=0.003$ ), studies on patients with acute ICH (OR: 1.89; 95\% CI: $1.23-2.91 ; P=0.004)$ or subacute ICH (OR: 1.56; 95\% CI: 1.26-1.93; $P<0.001$ ), studies using mRS 2-6 (OR: 2.31; 95\% CI: $1.55-3.45 ; P<0.001$ ) or 3-6 (OR: 1.28 ; 95\% CI: $1.07-1.54 ; P=0.007$ ) defined as poor functional outcome, and high-quality studies (OR: 1.51; 95\% CI: $1.01-2.27 ; P=0.045)$. Moreover, systolic $\mathrm{BP}$ variability by $\mathrm{CV}$ 
TABLE 1 | Characteristics of studies and patients included.

\begin{tabular}{|c|c|c|c|c|c|c|c|c|c|c|c|c|c|c|}
\hline Study & Country & Study design & $\begin{array}{l}\text { Sample } \\
\text { size }\end{array}$ & $\begin{array}{c}\text { Mean } \\
\text { age } \\
\text { (year) }\end{array}$ & $\begin{array}{c}\text { Male } \\
(\%)\end{array}$ & Stroke phase & $\begin{array}{l}\text { Systolic BP } \\
\text { targets }\end{array}$ & $\begin{array}{l}\text { Systolic BP } \\
\text { variability }\end{array}$ & $\begin{array}{l}\text { Time } \\
\text { from stroke } \\
\text { onset (h) }\end{array}$ & BP measurement & $\begin{array}{l}\text { Outcome } \\
\text { definition }\end{array}$ & $\begin{array}{l}\text { Follow- } \\
\text { up } \\
\text { (month) }\end{array}$ & Covariates adjusted & $\begin{array}{l}\text { Study } \\
\text { quality }\end{array}$ \\
\hline $\begin{array}{l}\text { SAMURAI- } \\
\text { ICH } 2014 \\
(30)\end{array}$ & Japan & $\begin{array}{l}\text { Prospective } \\
\text { observational } \\
\text { analysis }\end{array}$ & 205 & 65.0 & 61.0 & $\begin{array}{l}\text { Acute ICH (initial } \\
24 \mathrm{~h} \text { ) }\end{array}$ & $\begin{array}{l}<160 \mathrm{~mm} \\
\mathrm{Hg}\end{array}$ & SD and SV & $<3$ & $\begin{array}{l}\text { Casual cuff BP for } 24 \mathrm{~h} \text { (every } \\
15 \text { min during the first } 2 \mathrm{~h} \text {, and } \\
\text { every } 60 \text { min during the next } \\
22 \mathrm{~h} \text { ) }\end{array}$ & mRS 4-6 & 3.0 & $\begin{array}{l}\text { Sex, age, previous } \\
\text { antithrombotic medication, } \\
\text { initial systolic BP, initial heart } \\
\text { rate, initial NIHSS, onset to } \\
\text { treatment time, initial } \\
\text { hematoma volume, and } \\
\text { serum glucose level at } \\
\text { baseline }\end{array}$ & 7 \\
\hline $\begin{array}{l}\text { INTERACT2 } \\
2014 \text { (31) }\end{array}$ & International & $\begin{array}{l}\text { Observational } \\
\text { analysis (RCT } \\
\text { data) }\end{array}$ & 2645 & 63.5 & 62.1 & $\begin{array}{l}\text { Hyperacute (first } \\
24 \text { h)/acute ICH } \\
\text { (2-7 days) }\end{array}$ & $\begin{array}{l}<140 \mathrm{~mm} \\
\mathrm{Hg} \\
<180 \mathrm{~mm} \\
\mathrm{Hg}\end{array}$ & $\begin{array}{l}\text { SD, CV, ARV, } \\
\text { and RSD }\end{array}$ & $<6$ & $\begin{array}{l}\text { Casual cuff BP for the first } 24 \mathrm{~h} \\
\text { (every } 15 \mathrm{~min} \text { in the first hour, } \\
\text { every } 6 \mathrm{~h} \text { until } 24 \mathrm{~h} \text { ) }\end{array}$ & mRS 3-6 & 3.0 & $\begin{array}{l}\text { Age, sex, randomized group, } \\
\text { region, hematoma volume at } \\
\text { baseline, high scores on the } \\
\text { NIHSS, and mean systolic } \\
\text { BP during each period }\end{array}$ & 9 \\
\hline $\begin{array}{l}\text { ATACH-2 } \\
2018(32)\end{array}$ & USA & $\begin{array}{l}\text { Observational } \\
\text { analysis (RCT } \\
\text { data) }\end{array}$ & 913 & 62.1 & 61.7 & $\begin{array}{l}\text { Acute }(2- \\
24 \mathrm{~h}) / \text { subacute } \\
\mathrm{ICH}(2-7 \text { days })\end{array}$ & $\begin{array}{l}<140 \mathrm{~mm} \\
\mathrm{Hg} \\
<180 \mathrm{~mm} \\
\mathrm{Hg}\end{array}$ & $\begin{array}{l}\text { SD, CV, ARV, } \\
\text { SV, and RSD }\end{array}$ & $<48$ & $\begin{array}{l}\text { Casual cuff BP for the acute } \\
\text { (highest and lowest SBP/h) } \\
\text { and subacute period (the two } \\
\text { highest and lowest SBP } \\
\text { readings separated by } 1 \mathrm{~h} \text { for } \\
\text { days } 2,3 \text {, and } 7 \text { ) }\end{array}$ & mRS 3-6 & 3.0 & $\begin{array}{l}\text { Age, baseline NIHSS, } \\
\text { premorbid antihypertensive } \\
\text { medication, intraventricular } \\
\text { hemorrhage, and laterality of } \\
\text { ICH }\end{array}$ & 8 \\
\hline $\begin{array}{l}\text { Zhang } 2018 \\
\text { (33) }\end{array}$ & China & $\begin{array}{l}\text { Prospective } \\
\text { observational } \\
\text { analysis }\end{array}$ & 131 & 60.2 & 60.3 & $\begin{array}{l}\text { Acute ICH (first } \\
24 \mathrm{~h} \text { ) }\end{array}$ & NA & $\mathrm{SD}$ and $\mathrm{CV}$ & $<6$ & $\begin{array}{l}\text { Casual cuff BP every } 15 \mathrm{~min} \\
\text { from admission to } 1 \mathrm{~h} \text {, once } \\
\text { every } 30 \mathrm{~min} \text { from } 1 \text { to } 6 \mathrm{~h} \text {, and } \\
\text { once every hour from } 6 \text { to } 24 \mathrm{~h}\end{array}$ & mRS 2-6 & 3.0 & $\begin{array}{l}\text { Hypertension, DM, } \\
\text { metabolic syndrome, } \\
\text { smoking, and stroke history }\end{array}$ & 6 \\
\hline $\begin{array}{l}\text { Jeon } 2018 \\
(34)\end{array}$ & Korea & $\begin{array}{l}\text { Prospective } \\
\text { observational } \\
\text { analysis }\end{array}$ & 104 & 63.0 & 57.7 & $\begin{array}{l}\text { Acute } \mathrm{ICH} \\
\text { (within } 7 \text { days) }\end{array}$ & $\begin{array}{l}<140 \mathrm{~mm} \\
\mathrm{Hg}\end{array}$ & $\begin{array}{l}\mathrm{SD}, \mathrm{CV} \text {, and } \\
\mathrm{ARV}\end{array}$ & $<6$ & $\begin{array}{l}\text { BP was monitored every } \\
15 \text { min during the first } 2 \mathrm{~h} \text { and } \\
\text { hourly until the follow-up } \\
\text { computed tomography scan } \\
\text { and during the entire } \\
\text { admission period in the } \\
\text { intensive care units }\end{array}$ & mRS 3-6 & 3.0 & $\begin{array}{l}\text { Female, initial hematoma } \\
\text { volume, hypertension, LDL } \\
\text { cholesterol, mean BP, and } \\
\text { range }\end{array}$ & 6 \\
\hline $\begin{array}{l}\text { FAST-MAG } \\
2018 \text { (35) }\end{array}$ & USA & $\begin{array}{l}\text { Observational } \\
\text { analysis (RCT } \\
\text { data) }\end{array}$ & 386 & 65.5 & 66.6 & $\begin{array}{l}\text { Hyperacute (first } \\
4-6 \text { h)/acute } \\
\mathrm{ICH} \text { (first } \\
24-26 \mathrm{~h} \text { ) }\end{array}$ & NA & $\begin{array}{l}\mathrm{SD}, \mathrm{CV} \text {, and } \\
\mathrm{SV}\end{array}$ & $<2$ & $\begin{array}{l}\text { Casual cuff at } 11 \text { time points } \\
\text { (the first BP measurement was } \\
\text { performed at the time of first } \\
\text { paramedic patient } \\
\text { assessment; the second BP } \\
\text { assessment was performed on } \\
\text { ED arrival, before maintenance } \\
\text { study medication infusion, } \\
15 \text { min and } 1 \text { hour after the } \\
\text { start of the maintenance } \\
\text { infusion, and } 4,8,12,16,20 \text {, } \\
\text { and } 24 \mathrm{~h} \text { after ED arrival) } \\
\text { during the first } 24 \mathrm{~h}\end{array}$ & mRS 3-6 & 3.0 & $\begin{array}{l}\text { Baseline stroke severity, age, } \\
\text { presence of pre-stroke } \\
\text { disability, geographic region } \\
\text { of enrolling ambulance, sex, } \\
\text { BMI, CAD, alcohol habit, } \\
\text { blood urea nitrogen, eGFR, } \\
\text { hemoglobin, and mean } \\
\text { systolic BP }\end{array}$ & 9 \\
\hline $\begin{array}{l}\text { HeadPoST } \\
2019(36)\end{array}$ & International & $\begin{array}{l}\text { Observational } \\
\text { analysis (RCT } \\
\text { data) }\end{array}$ & 817 & 68.1 & 60.8 & $\begin{array}{l}\text { Acute ICH (first } \\
24 \mathrm{~h} \text { ) }\end{array}$ & NA & $\mathrm{CV}$ & $<24$ & $\begin{array}{l}\text { Casual cuff at 4-hourly } \\
\text { intervals during the first } 24 \mathrm{~h}\end{array}$ & mRS 3-6 & 3.0 & $\begin{array}{l}\text { Country, pre-stroke mRS } \\
\text { score, sex, baseline NIHSS } \\
\text { score, history of heart } \\
\text { disease, stroke, DM, or } \\
\text { hypertension, and prior } \\
\text { antiplatelet therapy }\end{array}$ & 8 \\
\hline
\end{tabular}

ARV, Average real variability; BMI: body mass index; BP, blood pressure; CAD: coronary artery disease; CV, coefficient of variation; DM: diabetes mellitus; eGFR: estimated glomerular filtration rate; ICH: intracerebral hemorrhage; $m R S$, modified Rankin Scale; NA: not available; NIHSS, National Institutes of Health Stroke Scale; RSD, residual standard deviation; SD, standard deviation; SV, successive variation. 
Study

ID

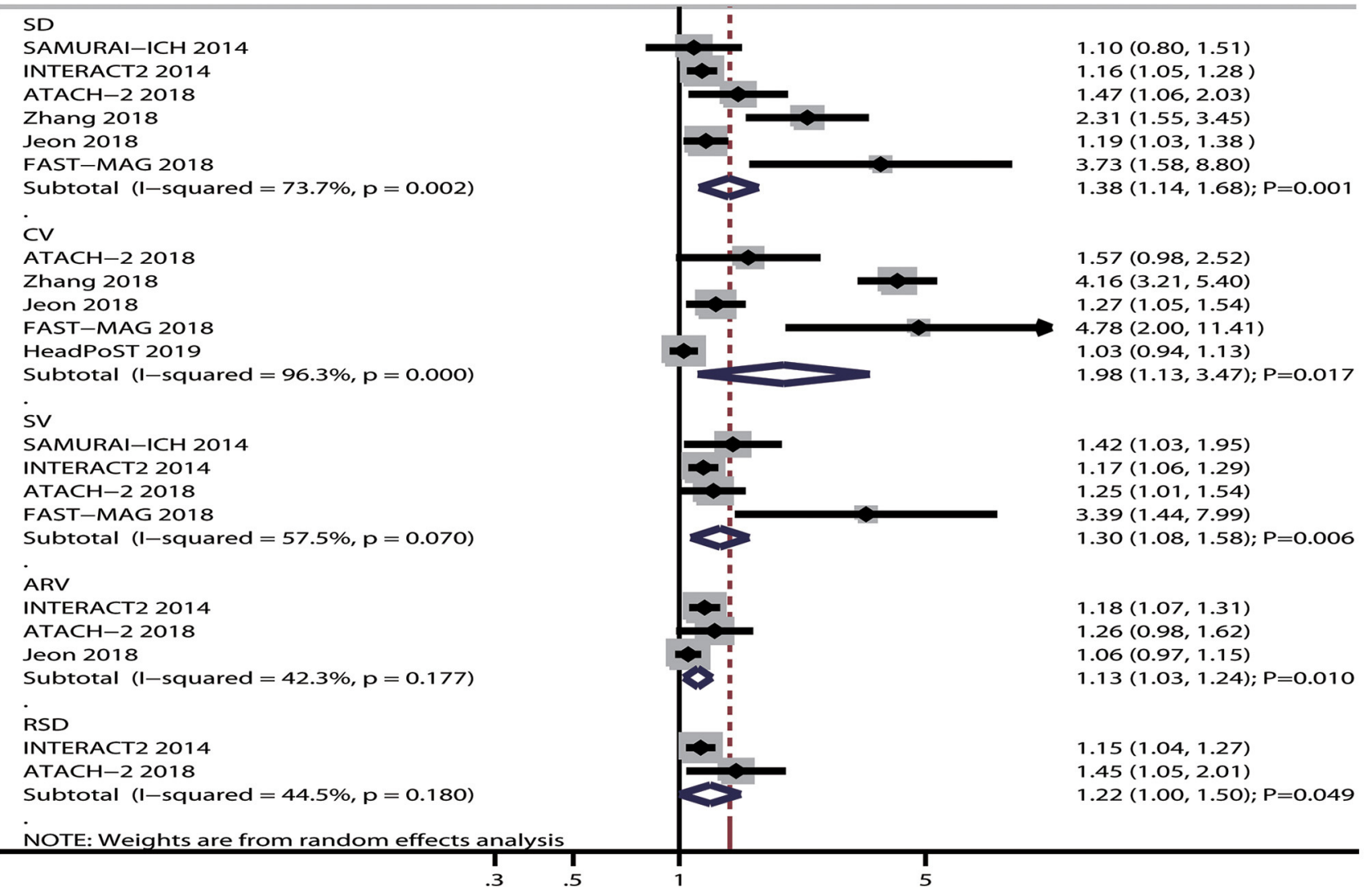

FIGURE 2 | Forest plot of the association between systolic BP variability and poor functional outcome.

was associated with an increased risk of poor functional outcomes in patients with hyperacute ICH (OR: 4.78; 95\% CI: 2.00-11.41; $P$ $<0.001$ ) and acute ICH (OR: 2.26; 95\% CI: 1.31-3.91; $P=0.003$ ), or subacute ICH (OR: 1.88; 95\% CI: 1.38-2.56; $P<0.001)$ and also in studies using mRS 2-6 (OR: 4.16; 95\% CI: 3.21-5.40; $P<$ 0.001 ) or 3-6 (OR: 1.40 ; 95\% CI: $1.02-1.93 ; P=0.038)$ defined as poor functional outcome.

\section{Publication Bias}

A review of the funnel plots could not rule out the potential for publication bias for the prognostic role of systolic BP variability by SD, CV, SV, and ARV in the risk of poor functional outcomes (Figure 4). No significant publication biases were observed for the role of systolic BP variability by $\mathrm{CV}$ ( $P$-value for Egger: 0.197; $P$-value for Begg: 0.221) and ARV ( $P$-value for Egger: 0.527; $P$-value for Begg: 1.000), but potential publication biases were noted for the role of systolic BP variability by SD ( $P$-value for Egger: 0.052; $P$-value for Begg: 0.060) and SV ( $P$-value for Egger: 0.043; $P$-value for Begg: 0.089). The conclusions were not changed after adjusting for publication bias using the trim-andfill method (37).

\section{DISCUSSION}

This systematic review and meta-analysis was based on prospective studies and explored all possible correlations between systolic BP variability and the risk of poor functional outcomes. This comprehensive quantitative analysis involved 5,201 patients with $\mathrm{ICH}$ from seven prospective studies across a wide range of characteristics, studies, and patients. The study showed that increased systolic BP variability was associated with an increased risk of poor functional outcomes for patients with ICH. The analysis of crude data indicated that most parameters of systolic $\mathrm{BP}$ variability (SD, CV, SV, and RSD) could cause excess risk of poor functional outcomes, while ARV did not affect the risk of poor functional outcomes. Moreover, subgroup analyses suggested that the prognostic value of systolic BP variability in the risk of poor functional outcomes was more evident in studies conducted in multiple countries, studies designed as a followup of randomized controlled trials, studies with a mean patient age of $<65.0$ years, studies involving patients with acute $\mathrm{ICH}$ or subacute ICH, studies using mRS 2-6 or 3-6 defined as poor functional outcomes and high-quality studies.

Several systematic reviews and meta-analyses have already illustrated the potential role of BP variability in the progression 
Study

ID
OR $(95 \% \mathrm{Cl})$

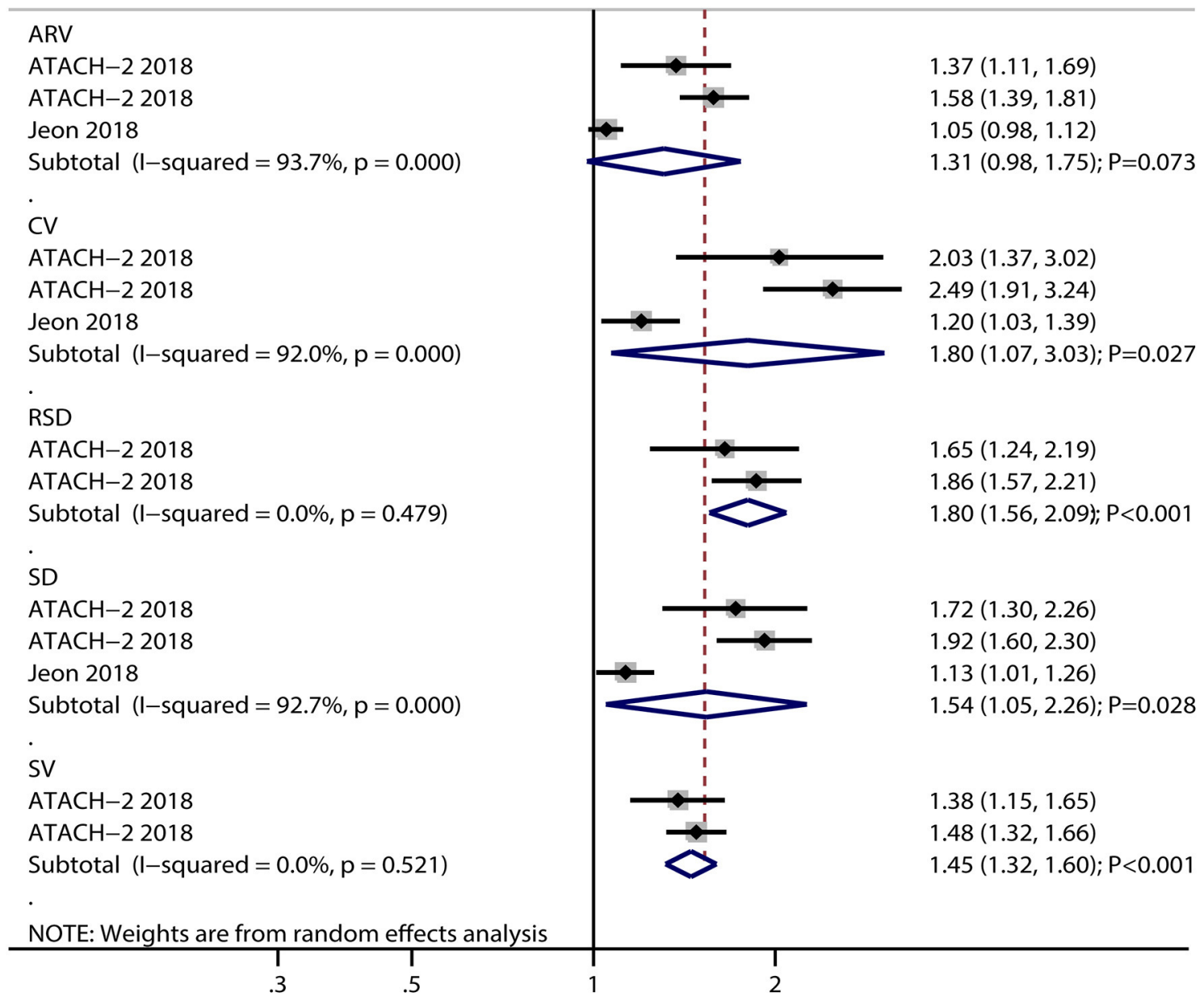

FIGURE 3 | Forest plot for the association of systolic BP variability with poor functional outcome based on crude data.

and prognosis of stroke (14-19). However, most studies focused on a general population and assessed the role of systolic BP variability in the primary prevention of the risk of subsequent stroke (14-18). Few studies included investigated the role of systolic BP variability for patients with ICH. Moullaali et al. performed a pooled analysis based on individual participant data and found that achieving early and stable systolic BP was associated with better outcomes for patients with ICH. The present analysis was based on the participants from INTERACT2 and ATACH-II trials $(31,32)$; additional trials were not included (38). The analysis involved all available prospective studies. Also, the BP measurement and the definition of stroke phase differed across included studies, thus playing an important role in significant heterogeneity among the included studies.

This study found that large systolic BP variability was associated with an increased risk of poor functional outcomes in patients with ICH. The potential reason for this could be the variability in BP when assessed using various indexes. The stability and reliability of the predictive model should be further explored using various indexes for assessing systolic
BP variability. Studies have already demonstrated that higher $\mathrm{BP}$ is associated with an increased risk of early deterioration, hematoma growth, and worse final functional outcome; lowering $\mathrm{BP}$ for patients with $\mathrm{ICH}$ should be recommended to prevent hemorrhage expansion in clinical practice (39-41). However, the results regarding the aggressive lowering of $\mathrm{BP}$ for patients with $\mathrm{ICH}$ were inconsistent $(42,43)$. Although BP variability was independently associated with poor functional outcomes after $\mathrm{ICH}$, this association depended on the time window $(31,44)$. Therefore, further studies should be conducted to explore the role of BP variability in measuring the time window for the prognosis of ICH.

Subgroup analyses found that the prognostic role of systolic $\mathrm{BP}$ variability in the risk of poor functional outcomes in patients with ICH was affected by country, study design, mean age, stroke type, outcome definition, and study quality. The potential reasons for this were as follows: (1) the study conducted in multiple countries included a large number of patients, and the results were stable; (2) data from the follow-up of randomized controlled trials were better than prospective cohort 
TABLE 2 | Sensitivity analysis for the risk of poor outcomes.

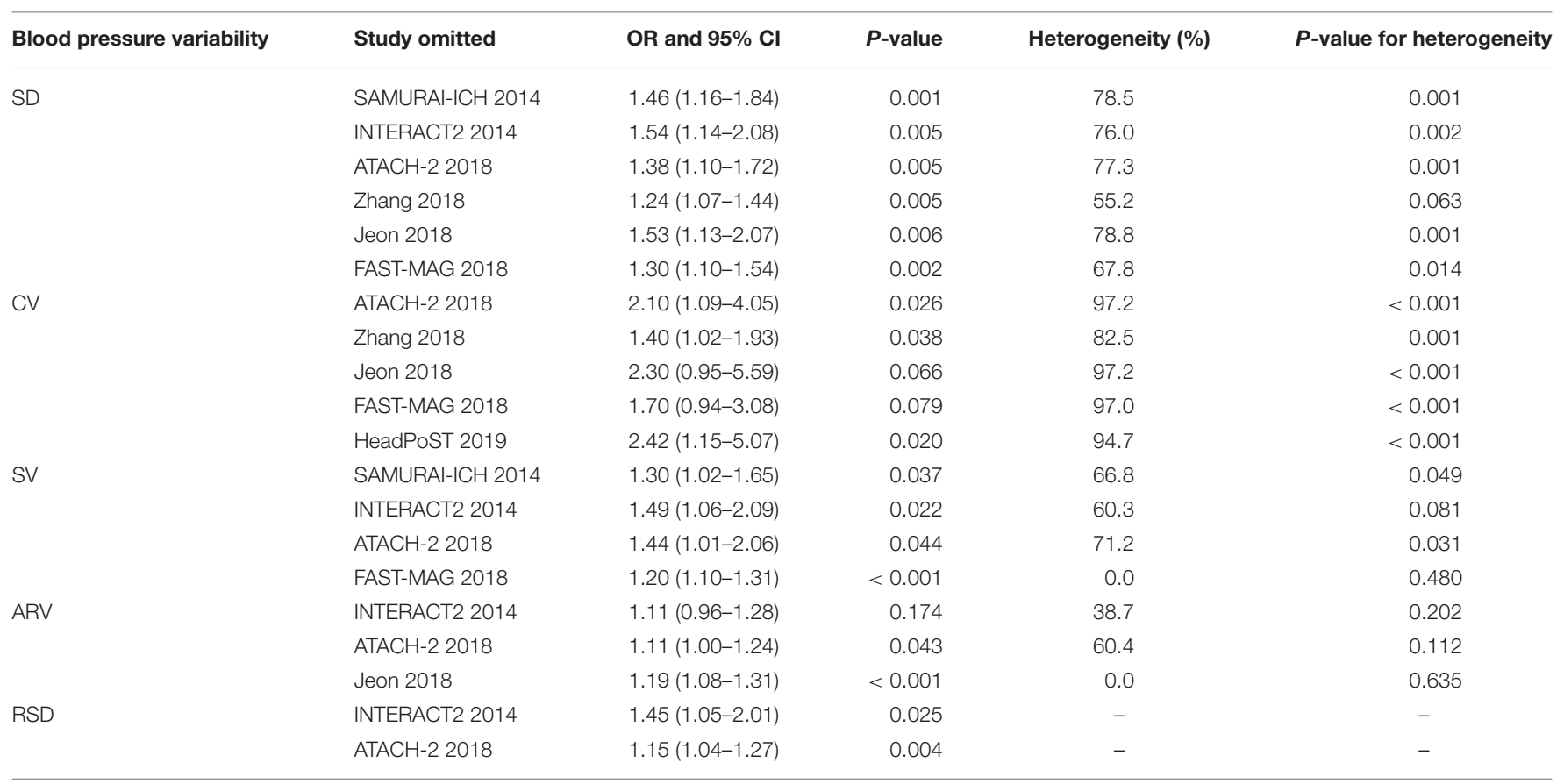

TABLE 3 | Subgroup analyses for the risk of poor outcome.

\begin{tabular}{|c|c|c|c|c|c|c|c|}
\hline BPV & Factors & Group & OR and $95 \% \mathrm{Cl}$ & $P$-value & Heterogeneity (\%) & $P$-value for heterogeneity & $P$-value between subgroups \\
\hline \multirow[t]{10}{*}{ SD } & Country & International & $1.16(1.05-1.28)$ & 0.003 & - & - & 0.082 \\
\hline & & USA & $2.14(0.88-5.25)$ & 0.095 & 74.7 & 0.047 & \\
\hline & & Asia & $1.40(0.97-2.01)$ & 0.070 & 80.1 & 0.007 & \\
\hline & Study design & Prospective observational & $1.40(0.97-2.01)$ & 0.070 & 80.1 & 0.007 & 0.582 \\
\hline & & RCT data & $1.51(1.01-2.27)$ & 0.045 & 76.9 & 0.013 & \\
\hline & Stroke phase & Hyperacute & $1.92(0.62-5.96)$ & 0.260 & 85.7 & 0.008 & 0.004 \\
\hline & & Acute & $1.89(1.23-2.91)$ & 0.004 & 95.9 & $<0.001$ & \\
\hline & & Subacute & $1.56(1.26-1.93)$ & $<0.001$ & - & - & \\
\hline & Outcome definition & mRS 2-6 & $2.31(1.55-3.45)$ & $<0.001$ & - & - & 0.006 \\
\hline & & mRS 3-6 & $1.28(1.07-1.54)$ & 0.007 & 65.4 & 0.034 & \\
\hline \multirow{10}{*}{$C V$} & & USA & $2.57(0.87-7.61)$ & 0.087 & 79.4 & 0.028 & \\
\hline & & Asia & $2.29(0.72-7.33)$ & 0.162 & 98.0 & $<0.001$ & \\
\hline & Study design & Prospective observational & $2.29(0.72-7.33)$ & 0.162 & 98.0 & $<0.001$ & $<0.001$ \\
\hline & & RCT data & $1.74(0.88-3.43)$ & 0.111 & 86.2 & 0.001 & \\
\hline & Mean age (year) & $\geq 65.0$ & $2.08(0.47-9.32)$ & 0.338 & 91.5 & 0.001 & $<0.001$ \\
\hline & & $<65.0$ & $2.03(0.88-4.68)$ & 0.096 & 96.2 & $<0.001$ & \\
\hline & Stroke phase & Hyperacute & $4.78(2.00-11.41)$ & $<0.001$ & - & - & 0.001 \\
\hline & & Acute & $2.26(1.31-3.91)$ & 0.003 & 96.3 & $<0.001$ & \\
\hline & & Subacute & $1.88(1.38-2.56)$ & $<0.001$ & - & - & \\
\hline & Outcome definition & mRS 2-6 & $4.16(3.21-5.40)$ & $<0.001$ & - & - & $<0.001$ \\
\hline
\end{tabular}




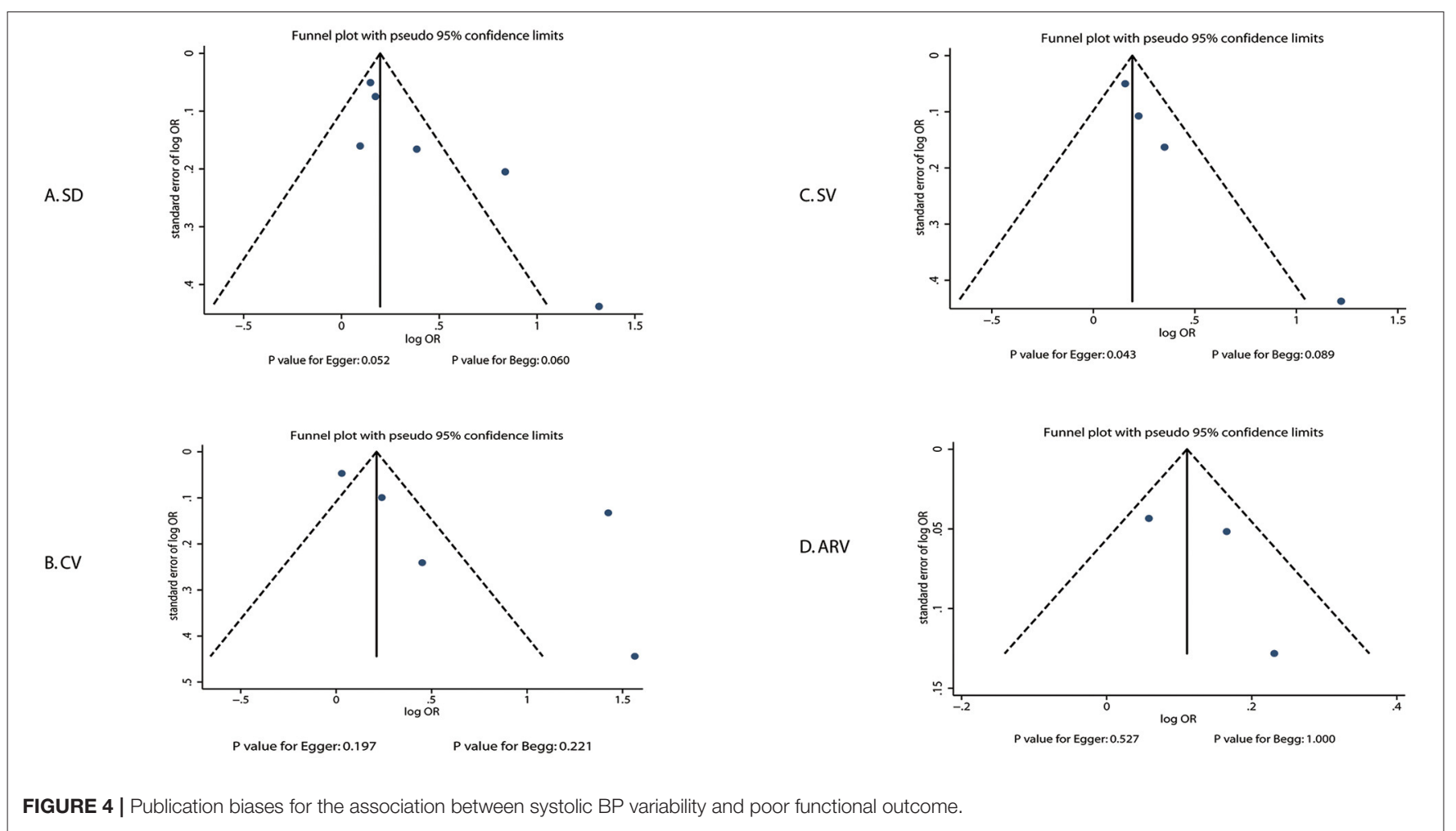

data because the confounders were well-controlled; (3) younger patients could better restore ability, and systolic BP variability was more stable in young patients than in elderly patients; 4) systolic BP variability for patients with ICH in various stages differed, and greater systolic BP variability for patients in super acute and acute stages might be associated with worse prognosis; (5) the definition of poor functional outcome could affect the events and was significantly related to the power to detect potential associations; and (6) the reliability of results significantly correlated with the study quality.

In the planning stage, the role of BP variability in the prognosis of ICH should be fully evaluated; however, only one trial reported the association between $\mathrm{BP}$ variability and hematoma growth (30). The results of this study confirmed the important feature for the monitoring of $\mathrm{BP}$ after $\mathrm{ICH}$, especially within 7 days. Moreover, the strength for the relationship between BP variability and prognosis of ICH were further explored in subgroup analyses. Further, the high-risk population should be monitored in clinical practice.

This study had several limitations. First, the included patients were in different stages, which could have affected the prognosis of ICH. Second, the heterogeneity across the studies included was not fully explained using sensitivity and subgroup analyses, which might be related to various outcome definitions, systolic BP targets, and background therapies. Third, the background therapies for managing hypertension differed across included studies, which might have influenced BP variability and outcomes. Fourth, various covariates were adjusted among the studies included, and these covariates might have affected the prognosis of ICH. Fifth, all of the studies included investigated the role of systolic BP variability in ICH in hyperacute, acute, and subacute stages; no study focused on patients in other stages. Sixth, the analysis was based on pooled data, and the detailed analyses were restricted. Finally, this study was based on published studies, and hence publication bias was inevitable.

In conclusion, this study showed that large systolic BP variability was associated with an increased risk of poor functional outcomes in patients with ICH. Moreover, the prognostic role of systolic BP variability could be affected by country, study design, mean age, stroke type, outcome definition, and study quality. These conclusions suggested that increased intraindividual fluctuation of systolic BP should be cautiously managed to improve the prognosis of ICH. Further large-scale prospective studies should be conducted to assess the stability of the predictive model for the systolic BP variability in patients with ICH.

\section{DATA AVAILABILITY STATEMENT}

The original contributions presented in the study are included in the article/supplementary material, further inquiries can be directed to the corresponding author/s.

\section{AUTHOR CONTRIBUTIONS}

WL and LZ carried out the experiments, participated in collecting data, and drafted the manuscript. XZ performed statistical analysis and participated in its design. All authors read and approved the final manuscript. 


\section{REFERENCES}

1. Naghavi M, Abajobir AA, Abbafati C, Abbas KM, Abd-Allah F, Abera SF, et al. Global, regional, and national age-sex specific mortality for 264 causes of death, 1980-2016: a systematic analysis for the global burden of disease study 2016. Lancet. (2017) 390:1151-210. doi: 10.1016/S0140-6736(17)32152-9

2. Wallin MT, Culpepper WJ, Nichols E, Bhutta ZA, Gebrehiwot TT, Hay SI, et al. Global, regional, and national burden of multiple sclerosis 1990-2016: a systematic analysis for the global burden of disease study 2016. Lancet Neurol. (2019) 18:269-85. doi: 10.1016/S1474-4422(18)30443-5

3. Sennfält S, Norrving B, Petersson J, Ullberg T. Long-term survival and function after stroke. Stroke. (2018). doi: 10.1161/STROKEAHA.118022913. [Epub ahead of print].

4. An SJ, Kim TJ, Yoon BW. Epidemiology, risk factors, and clinical features of intracerebral hemorrhage: an update. J Stroke. (2017) 19:3-10. doi: 10.5853 /jos. 201600864

5. Gross BA, Jankowitz BT, Friedlander RM. Cerebral intraparenchymal hemorrhage: a review. JAMA. (2019) 321:1295-303. doi: 10.1001/jama.20192413

6. Qureshi AI, Tuhrim S, Broderick JP, Batjer HH, Hondo H, Hanley DF. Spontaneous intracerebral hemorrhage. N Engl J Med. (2001) 344:1450-60. doi: 10.1056/NEJM200105103441907

7. van Asch CJ, Luitse MJ, Rinkel GJ, van der Tweel I, Algra A, Klijn CJ. Incidence, case fatality, and functional outcome of intracerebral haemorrhage over time, according to age, sex, and ethnic origin: a systematic review and meta-analysis. Lancet Neurol. (2010) 9:167-76. doi: 10.1016/S1474-4422(09)70340-0

8. Godoy DA, Piñero G, Di Napoli M. Predicting mortality in spontaneous intracerebral hemorrhage: can modification to original score improve the prediction? Stroke. (2006) 37:1038-44. doi: 10.1161/01.STR.0000206441.7964649

9. Minutolo R, Agarwal R, Borrelli S, Chiodini P, Bellizzi V, Nappi F, et al. Prognostic role of ambulatory blood pressure measurement in patients with nondialysis chronic kidney disease. Arch Inter Med. (2011) 171:1090-8. doi: 10.1001/archinternmed.2011230

10. Gabbai FB, Rahman M, Hu B, Appel LJ, Charleston J, Contreras G, et al. Relationship between ambulatory BP and clinical outcomes in patients with hypertensive CKD. Clin J Am Soc Nephrol CJASN. (2012) 7:1770-6. doi: 10.2215/CJN11301111

11. Mancia G, Bombelli M, Facchetti R, Madotto F, Corrao G, Trevano FQ, et al. Long-term prognostic value of blood pressure variability in the general population: results of the pressioni arteriose monitorate e loro associazioni study. Hypertension. (2007) 49:1265-70. doi: 10.1161/HYPERTENSIONAHA.107088708

12. Hansen TW, Thijs L, Li Y, Boggia J, Kikuya M, Björklund-Bodegård K, et al. Prognostic value of reading-to-reading blood pressure variability over 24 hours in 8938 subjects from 11 populations. Hypertension. (2010) 55:1049-57. doi: 10.1161/HYPERTENSIONAHA.109140798

13. Palatini P, Reboldi G, Beilin LJ, Casiglia E, Eguchi K, Imai Y, et al. Added predictive value of night-time blood pressure variability for cardiovascular events and mortality: the ambulatory blood pressure-international study. Hypertension. (2014) 64:487-93. doi: 10.1161/HYPERTENSIONAHA.11403694

14. Tai C, Sun Y, Dai N, Xu D, Chen W, Wang J, et al. Prognostic significance of visit-to-visit systolic blood pressure variability: a meta-analysis of 77,299 patients. J Clin Hypertens. (2015) 17:107-15. doi: 10.1111/jch12484

15. Stevens SL, Wood S, Koshiaris C, Law K, Glasziou P, Stevens RJ, et al. Blood pressure variability and cardiovascular disease: systematic review and metaanalysis. BMJ (Clinical research ed). (2016) 354:i4098. doi: 10.1136/bmji4098

16. Wang J, Shi X, Ma C, Zheng H, Xiao J, Bian H, et al. Visit-to-visit blood pressure variability is a risk factor for all-cause mortality and cardiovascular disease: a systematic review and meta-analysis. J Hypertens. (2017) 35:10-7. doi: 10.1097/HJH0000000000001159

17. Wang H, Li M, Xie SH, Oyang YT, Yin M, Bao B, et al. Visit-to-visit systolic blood pressure variability and stroke risk: a systematic review and metaanalysis. Curr Med Sci. (2019) 39:741-7. doi: 10.1007/s11596-019-2100-9

18. Ma Y, Song A, Viswanathan A, Blacker D, Vernooij MW, Hofman A, et al. Blood pressure variability and cerebral small vessel disease: a systematic review and meta-analysis of population-based cohorts. Stroke. (2020) 51:82-9. doi: 10.1161/STROKEAHA.119026739

19. Manning LS, Rothwell PM, Potter JF, Robinson TG. Prognostic significance of short-term blood pressure variability in acute stroke: systematic review. Stroke. (2015) 46:2482-90. doi: 10.1161/STROKEAHA.115010075

20. Stroup DF, Berlin JA, Morton SC, Olkin I, Williamson GD, Rennie D, et al. Meta-analysis of observational studies in epidemiology: a proposal for reporting. Meta-analysis of observational studies in epidemiology (MOOSE) group. JAMA. (2000) 283:2008-12. doi: 10.1001/jama.283.152008

21. Wells G, Shea B, O'Connell D. The Newcastle-Ottawa Scale (NOS) for Assessing the Quality of Nonrandomised Studies in Meta-Analyses. Ottawa, ON: Ottawa Hospital Research Institute (2019). Available online at: http://www.ohri.ca/ programs/clinical_epidemiology/oxford.htm

22. DerSimonian R, Laird N. Meta-analysis in clinical trials. Control Clin Trials (1986) 7:177-88. doi: 10.1016/0197-2456(86)90046-2

23. Ades AE, Lu G, Higgins JP. The interpretation of random-effects meta-analysis in decision models. Med Decis Mak. (2005) 25:646-54. doi: 10.1177/0272989X05282643

24. Deeks JJ, Higgins JPT, Altman DG. Analyzing data and undertaking metaanalyses. In: Higgins J, Green S, editors. Cochrane Handbook for Systematic Reviews of Interventions. Oxford: The Cochrane Collaboration (2008). Available online at: https://training.cochrane.org/handbook/archive/v5.0.0/

25. Higgins JP, Thompson SG, Deeks JJ, Altman DG. Measuring inconsistency in meta-analyses. BMJ. (2003) 327:557-60. doi: 10.1136/bmj.327.74 14557

26. Tobias A. Assessing the influence of a single study in the meta-analysis estimate. Stata Tech Bull. (1999) 47:15-7.

27. Altman DG, Bland JM. Interaction revisited: the difference between two estimates. BMJ. (2003) 326:219. doi: 10.1136/bmj.326.7382219

28. Egger M, Davey Smith G, Schneider M, Minder C. Bias in metaanalysis detected by a simple, graphical test. BMJ. (1997) 315:629-34. doi: 10.1136/bmj.315.7109629

29. Begg CB, Mazumdar M. Operating characteristics of a rank correlation test for publication bias. Biometrics. (1994) 50:1088-101. doi: 10.2307/25 33446

30. Tanaka E, Koga M, Kobayashi J, Kario K, Kamiyama K, Furui E, et al. Blood pressure variability on antihypertensive therapy in acute intracerebral hemorrhage: the Stroke Acute Management with Urgent Riskfactor Assessment and Improvement-intracerebral hemorrhage study. Stroke. (2014) 45:2275-9. doi: 10.1161/STROKEAHA.114005420

31. Manning L, Hirakawa Y, Arima H, Wang X, Chalmers J, Wang J, et al. Blood pressure variability and outcome after acute intracerebral haemorrhage: a post-hoc analysis of INTERACT2, a randomised controlled trial. Lancet Neurol. (2014) 13:364-73. doi: 10.1016/S1474-4422(14) 70018-3

32. de Havenon A, Majersik JJ, Stoddard G, Wong KH, McNally JS, Smith AG, et al. Increased blood pressure variability contributes to worse outcome after intracerebral hemorrhage. Stroke. (2018) 49:1981-4. doi: 10.1161/STROKEAHA.118022133

33. Zhang HX, Fan QX, Xue SZ, Zhang M, Zhao JX. Twenty-four-hour blood pressure variability plays a detrimental role in the neurological outcome of hemorrhagic stroke. J Int Med Res. (2018) 46:2558-68. doi: 10.1177/0300060518760463

34. Jeon JP, Kim C, Kim SE. Blood pressure variability and outcome in patients with acute nonlobar intracerebral hemorrhage following intensive antihypertensive treatment. Chin Med J. (2018) 131:657-64. doi: 10.4103/0366-6999226886

35. Chung PW, Kim JT, Sanossian N, Starkmann S, Hamilton S, Gornbein J, et al. Association between hyperacute stage blood pressure variability and outcome in patients with spontaneous intracerebral hemorrhage. Stroke. (2018) 49:34854. doi: 10.1161/STROKEAHA.117017701

36. Minhas JS, Wang X, Lavados PM, Moullaali TJ, Arima H, Billot L, et al. Blood pressure variability and outcome in acute ischemic and hemorrhagic stroke: a post hoc analysis of the HeadPoST study. J Hum Hypertens. (2019) 33:411-8. doi: 10.1038/s41371-019-0193-Z

37. Duvall S, Tweedie R. A nonparametric "trim and fill" method for assessing publication bias in meta-analysis. J Am Stat Assoc. (2000) 95:89-98. doi: 10.1080/01621459.200010473905 
38. Moullaali TJ, Wang X, Martin RH, Shipes VB, Robinson TG, Chalmers J, et al. Blood pressure control and clinical outcomes in acute intracerebral haemorrhage: a preplanned pooled analysis of individual participant data. Lancet Neurol. (2019) 18:857-64. doi: 10.1016/S1474-4422(19)30196-6

39. Ohwaki K, Yano E, Nagashima H, Hirata M, Nakagomi T, Tamura A. Blood pressure management in acute intracerebral hemorrhage: relationship between elevated blood pressure and hematoma enlargement. Stroke. (2004) 35:1364-7. doi: 10.1161/01.STR.0000128795.382834b

40. Leira R, Dávalos A, Silva Y, Gil-Peralta A, Tejada J, Garcia M, et al. Early neurologic deterioration in intracerebral hemorrhage: predictors and associated factors. Neurology. (2004) 63:461-7. doi: 10.1212/01.WNL.0000133204.81153AC

41. Hemphill JC, 3rd, Greenberg SM, Anderson CS, Becker K, Bendok BR, Cushman M, et al. Guidelines for the management of spontaneous intracerebral hemorrhage: a guideline for healthcare professionals from the American heart association/American stroke association. Stroke. (2015) 46:2032-60. doi: 10.1161/STR0000000000000069

42. Anderson CS, Heeley E, Huang Y, Wang J, Stapf C, Delcourt C, et al. Rapid blood-pressure lowering in patients with acute intracerebral hemorrhage. $N$ Engl J Med. (2013) 368:2355-65. doi: 10.1056/NEJMoa1214609
43. Qureshi AI, Palesch YY, Barsan WG, Hanley DF, Hsu CY, Martin RL, et al Intensive blood-pressure lowering in patients with acute cerebral hemorrhage. N Engl J Med. (2016) 375:1033-43. doi: 10.1056/NEJMoa1603460

44. Manning LS, Mistri AK, Potter J, Rothwell PM, Robinson TG. Short-term blood pressure variability in acute stroke: post hoc analysis of the controlling hypertension and hypotension immediately post stroke and continue or stop post-stroke antihypertensives collaborative study trials. Stroke. (2015) 46:1518-24. doi: 10.1161/STROKEAHA.115009078

Conflict of Interest: The authors declare that the research was conducted in the absence of any commercial or financial relationships that could be construed as a potential conflict of interest.

Copyright (c) 2021 Liu, Zhuang and Zhang. This is an open-access article distributed under the terms of the Creative Commons Attribution License (CC BY). The use, distribution or reproduction in other forums is permitted, provided the original author(s) and the copyright owner(s) are credited and that the original publication in this journal is cited, in accordance with accepted academic practice. No use, distribution or reproduction is permitted which does not comply with these terms. 